\section{Lebensfreude senkt die Mortalität}

Was wir schon immer geahnt haben, ist nun wissenschaftlich erwiesen: Wer anhaltend Lebensglück verspürt, kann damit rechnen, dass er länger lebt als freudlose Menschen. n der English Longitudinal Study of Ageing (ELSA) werden seit $2002 \mathrm{Ge}$ sundheitszustand und psychosoziale $\mathrm{Pa}$ rameter von 9.365 repräsentativ ausgewählten Personen ab 50 (initial im Schnitt $63 \pm 9,3$ Jahre) prospektiv untersucht. 2002, 2004 und 2006 erhielten sie vier Fragen zur Lebensfreude aus dem CASP-19-Inventar zur Lebensqualität: _, Ich habe Freude an den Dingen, die ich tue."

_„Ich habe Freude daran, mit anderen zusammen zu sein.“

_,Wenn ich alles bedenke, so sehe ich auf mein Leben mit einem Gefühl von Glück zurück.“

_, „Ich fühle mich in diesen Tagen voller Energie."

24\% der Probanden bekundeten bei keiner der drei Befragungen große Lebensfreude, $20 \%$ nur bei einer, $22 \%$ bei zwei und $34 \%$ bei allen drei Befragungen. 1.310 Personen verstarben im Beobachtungszeitraum. Die Mortalität war „do-

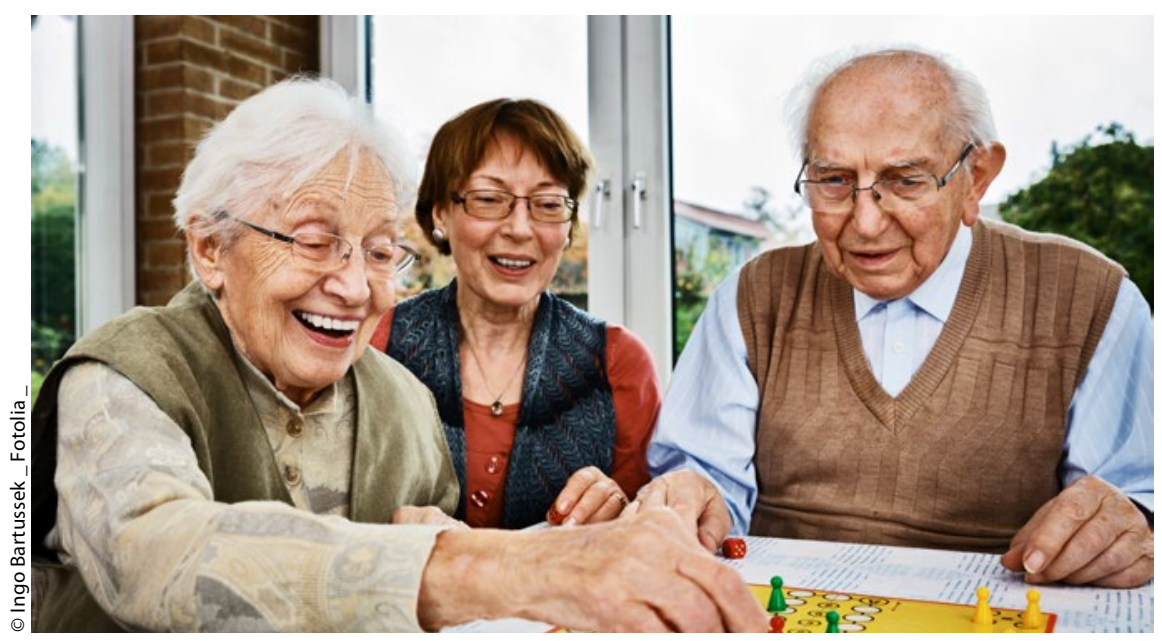

sisabhängig" invers assoziiert mit der Zahl der Angaben über große Lebensfreude. Im Vergleich zu Menschen ohne Lebensfreude lag die Hazard Ratio für die Gesamtmortalität bei zwei Lebensfreude-Angaben bei 0,83 , bei drei positiven Angaben sogar nur bei 0,76. Diese Assoziation blieb bestehen, wenn man den Gesundheitszustand bei Studienbeginn, demografische Faktoren, Mobilitätseinschränkungen und depressive Symptome berücksichtigte. Die Assoziation blieb auch erhalten, wenn man alle Todesfälle innerhalb von zwei Jahren nach der dritten Befragung ausschloss. Das spricht dagegen, dass z.B. eine schwerwiegende Erkrankung oder der terminale Abbau das Lebensglück beeinträchtigten.

Zaninotto P, Wardle J, Steptoe A et al. Sustained enjoyment of life and mortality at older ages: analysis of the English longitudial study of ageing. BMJ. 2016;355:i6267

\section{Kommentar}

Über die Ursachen des Phänomens sagt diese Beobachtungsstudie naturgemäß nichts aus. So wurde mit einer aufwändigen Untersuchung das ziemlich Naheliegende bestätigt. Man fragt sich auch, welche Konsequenzen wir daraus ziehen sollen. Wie soll man es bewerkstelligen, am Lebensende auf ein erfülltes Leben zurückschauen zu können?

Prof. Dr. Füßl, München

\section{Übergewichtige Mädchen pubertieren früher}

\section{Übergewicht im Kindesalter führt bei Mädchen offenbar zu einem früheren Einsetzen der Pubertät. Zu dicke Jungen pubertieren dagegen eher später. Wissenschaftler der Uni Witten-Herdecke haben Hinweise darauf gefunden, womit dies möglicherweise zusammenhängt.}

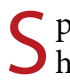
pekulationen über den Zusammenhang von BMI und Pubertätsbeginn gibt es schon seit einigen Jahren. Wie bereits frühere Studien nahelegten, scheint dabei das von adipösem Gewebe sezernierte Leptin eine Schlüsselrolle zu spielen. Das Zytokin nimmt offenbar Einfluss auf die Hypothalamus-Hypophysen-Gonaden-Achse.
Diese Hypothese wird nun untermauert durch eine Longitudinalstudie unter Beteiligung der Universität Witten-Herdecke. Die Teilnehmer waren 160 übergewichtige Kinder, Jungen und Mädchen, bei denen die Pubertät noch nicht eingesetzt hatte. Die Mädchen waren bei Studienbeginn zwischen neun und elf Jahre alt, die Jungen, bei denen generell mit ei- nem späteren Pubertätsbeginn zu rechnen ist, zwischen elf und dreizehn. Kinder mit einem BMI über der 90. altersentsprechenden Perzentile wurden als übergewichtig definiert. Als adipös galten Kinder, wenn ihr BMI jenseits der 97. Perzentile lag.

Alle Kinder nahmen ein Jahr lang am sogenannten „Obeldicks"-Programm teil, einer durch Fachpersonal angeleiteten ambulanten Intervention mit dem Ziel einer nachhaltigen Lebensstiländerung. Die Bausteine sind Schulungen und Programme zur Förderung der körperlichen Aktivität und zur gesunden Ernährung, ergänzt durch Verhaltensmaßnahmen und eine psychologische 